دراسة إنتقادية للمحاسبة عن الضرببة علي القيمة المضافة في قطاع الخدمات المهنية والإستشارية

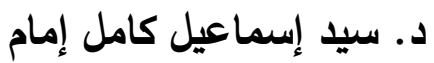

مدرس المحاسبة بمعه العبور

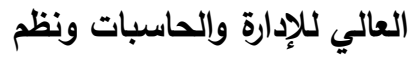

المعلومات

المُستخلص

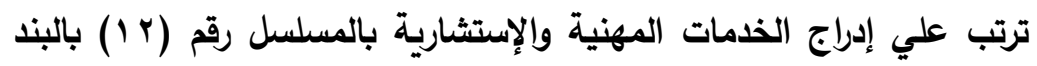

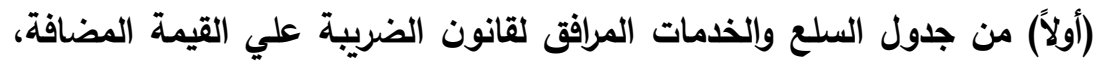

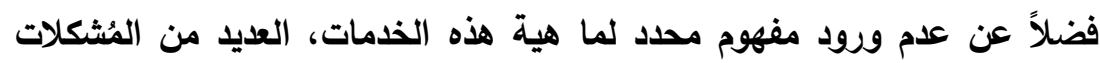
وذلك علي مستوي كلٍ من الإدارة الضريبية والمجتمع الضريبي علي حذٍ سواء.

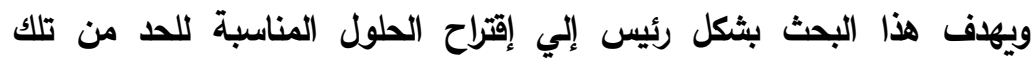

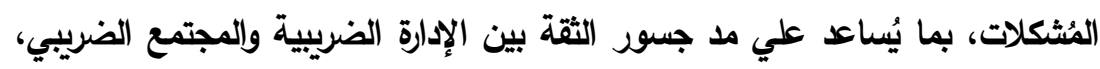
فضلاً عن تعظيم الإيرادات الضريبية.

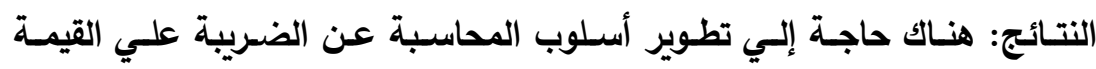
المضافة في قطاع الخدمات المهنية والإستثارية.

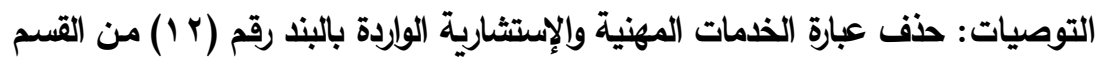

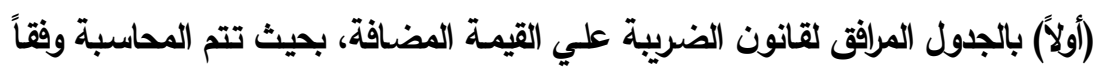

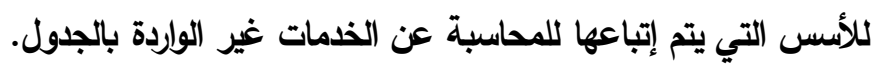

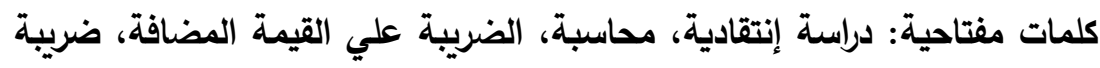
الجدول، مشكلات ضريبية، الإدارة الضريبية، الخدمات المهنية والإستشارية، الإيرادات الضريبية، المجتمع الضريبي، أسلوب محاسبة. 


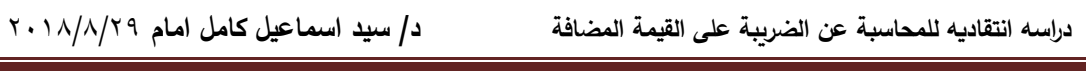

Critical study of accounting for value added tax In the professional and advisory services sector Abstract

The inclusion of professional and advisory services in the series (12) in item (I) of the table of goods and services accompanying the VAT law, as well as the lack of a specific concept of these services, led to many problems at the level of both the tax administration and the tax community.

The main aim of this research is to propose appropriate solutions to reduce these problems, thus helping to build confidence between the tax administration and the tax community, as well as maximizing tax revenues.

Results: There is a need to develop the method of accounting for value added tax in the professional and consulting services sector.

Recommendations: Deletion of Professional and Consulting Services mentioned in item (12) of section (I) in the table accompanying the VAT law, so that accounting is done according to the basis for accounting for services not listed in the table.

Keywords: Critical study, Accounting, Value Added Tax, Table tax, Tax problems, Tax administration, Professional and Consulting Services, Tax revenues, Tax community, Method of accounting. 


\section{جدول التعاريف}

\begin{tabular}{|c|c|}
\hline 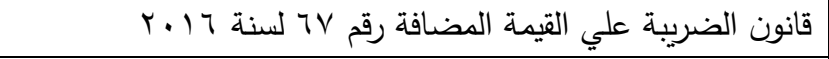 & 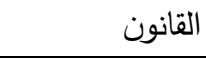 \\
\hline الكوجب قرار وزير التنيذية لقانون الضريبة علي القيمة المضافة الصادرة & 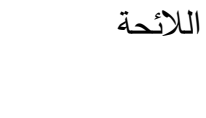 \\
\hline الضريبة علي القيمة المضافة & 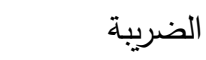 \\
\hline جدول السلع والخدمات المرافق للقانون & 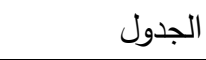 \\
\hline 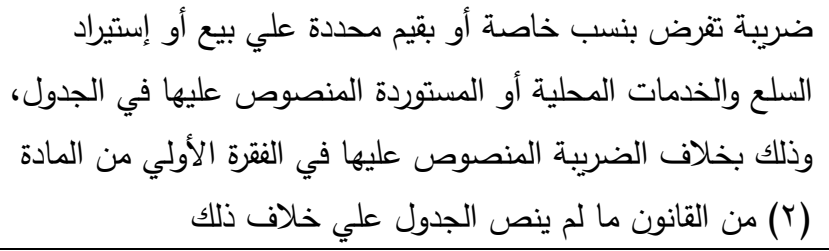 & 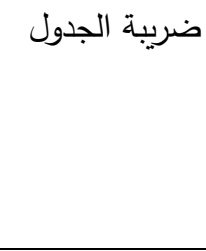 \\
\hline مصلحة الضرائب المصرية (قيمة مضافة) & الإدارة الضريبية \\
\hline وزير المالية & 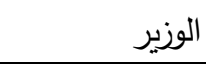 \\
\hline 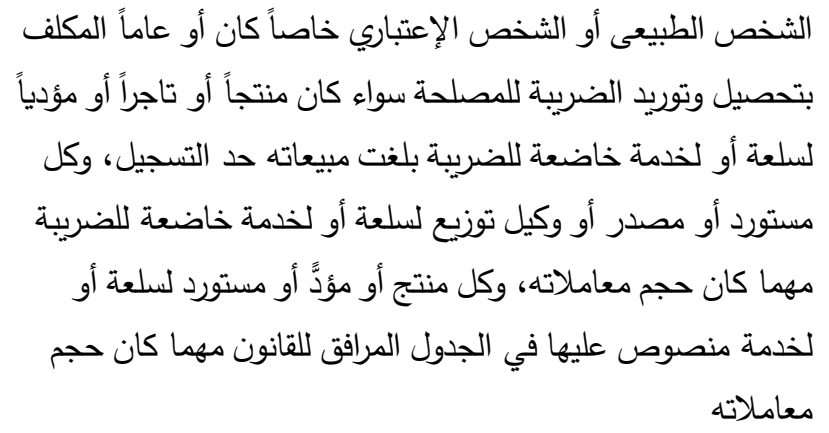 & 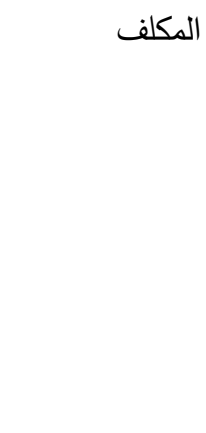 \\
\hline
\end{tabular}




\section{أولاً: الإطار العام للبحث}

1- 1 - مُشكلة البحث

ترتب علي إدراج الخدمات المهنية والإستشارية بالمسلسل رقم (Y I ( بالبند (أولاً)

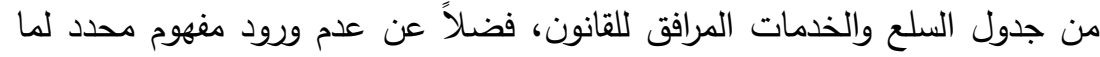
هية هذه الخدمات، العديد من المُشكلات وذلك علي مستوي كلٍ من الإدارة الضريبية

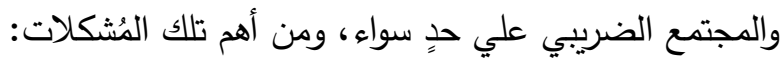

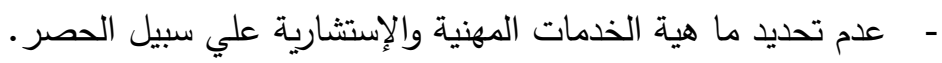

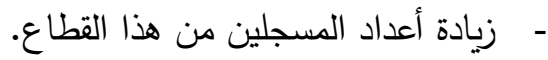
- - - - - مارتفاع تكلفة تحصيل الضريبة. - - - زيادة الأعباء الإدارية لكلٍ من الإدارة الضريبية والمسجلين من هذا القطاع.

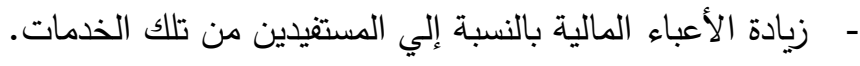

$$
\text { - عدم خصم الضريبة علي الدذخلات. }
$$

بناءً علي ما تقدم يُمكن طرح مشكلة البحث من خلال التساؤلات التالية: أ- هل هناك حاجة إلي تطوير أسلوب المحاسبة عن الضريبة علي القيمة

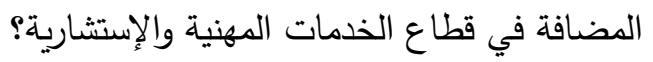

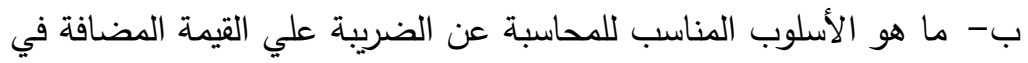

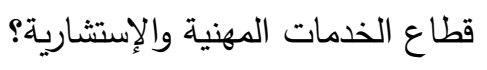

وهو ما يحاول الباحث الإجابة عنه من خلال هذا البحث.

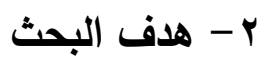

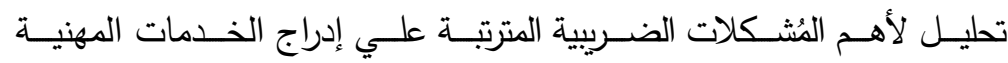

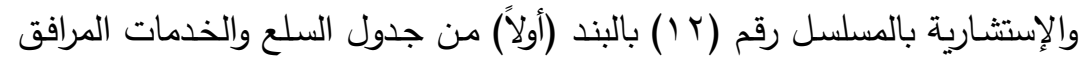

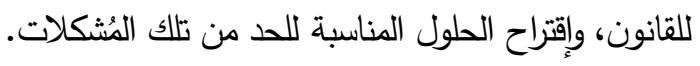




\section{r- (أهمية البحث \\ أ- الأهمية العلمية}

طبقاً للدراسـات المتاحة في مجال الضريبة علي القيمة المضافة -في حدود علم الباحث - يتضـح نــرة الدراسـات التي تتاولت مشكلات المحاسبة في قطـاع الخدمات

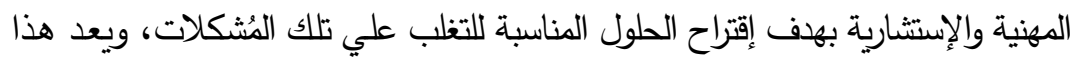
البحث خطوة في هذا الإتجاه.

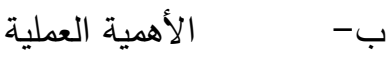

تتبع أهمية البحث من الناحية العملية في محاولة الوصول إلي الأسلوب المناسب الفبد الفية

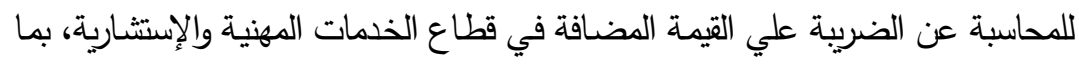
يعمل علي مد جسور الثقة بين الإدارة الضريبية والمجتمع الضريبي، فضلاً عن تعظيم الإيرادات الضريبية.

ـ - منهج البحث

تحقيقاً لأهداف الدراسة سوف يتبع الباحث المنهج التحليلي، وذلك من خلال

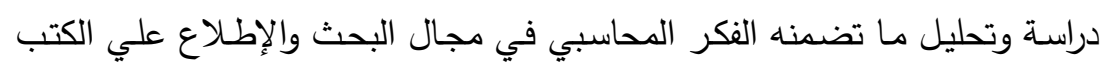

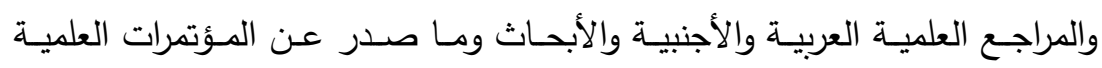

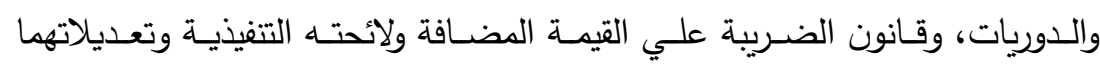

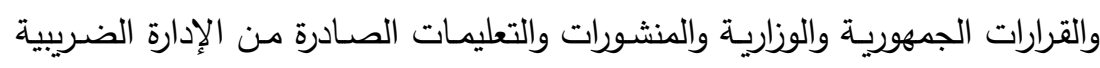
ذات الصلة بموضوع البحث.

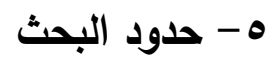

أ- حدود موضوعية

يقتصر البحث علي دراسـة وتحليل مُشكلات المحاسبة عن الضريبة علي القيمة المضافة في قطاع الخدمات المهنية والإستشارية. 


$$
\text { ب- حدود مكانية }
$$

يقتصـر البحث علي قطـاع الخدمات المهنيـة والإستشـارية في جمهوريـة

$$
\text { مصر العربية. }
$$

ج- جدود زمنية

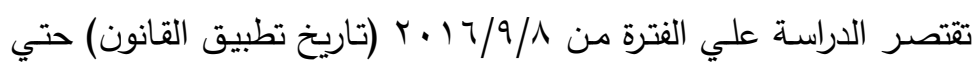

إبريل 1 1 • ب (تاريخ الإنتهاء من إعداد البحث).

7- - خطة البحث

تحقياً لأهداف البحث، فقد تم تقسيمه إلي العناصر التالية:

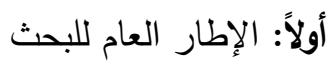

ثانياً: ماهية الخدمات المهنية والإستشارية

ثالثاً: الإطار العام للمحاسبة عن الضريبة علي القيمة المضافة في قطاع الخدمات

$$
\text { المهنية والإستشارية }
$$

رابعاً: مشكلات المحاسبة عن الضريبة علي القيمة المضافة في قطاع الخدات المهنية والإستشارية

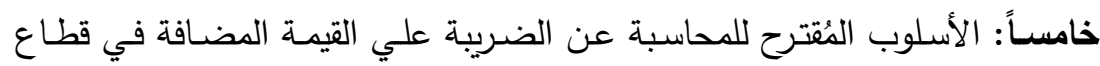
الخدمات المهنية والإستشارية سادساً: الخلاصة والنتائج والتوصيات والإنداته

$$
\text { الدراسعات المستثبلية }
$$




\section{ثانياً: ماهية الخدمات المهنية والإستشارية}

يُقصد بالخدمات المهنية والإستشارية الخدمات ذات الطبيعة غير التجارية أو

الصناعية التي يؤديها الشخص الطبيعي أو الإعتباري بصفة مستقلة ويكون

$$
\text { العنصر الأساسي فيها العمل. (المادة رقم VV من اللائحة) }
$$

وبالنظر للضريبة علي إيرادات المهن غير التجارية، نجد أن المشرع قد أورد

لفظ المهن غير التجارية والمهن الحرة كمتردفان، أما الإدارة الضريبية فقد حددت إئات

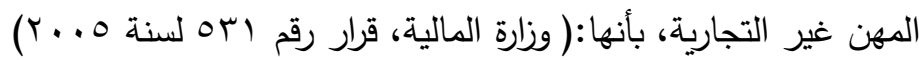

$$
\text { r- }
$$

r- الهندسة (بما في ذلك الهندسة الزراعية).

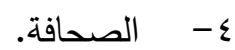

0 - تأليف المصنفات العلمية والأدبية بما في ذلك إلقاء الأحاديث الفنية

$$
\text { والعلمية والأدبية. }
$$

$$
\text { 7- - المحاسبة والمراجعة. }
$$

- - - - الخبرة بما في ذلك مهنة الخبير المثمن.

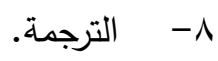

$$
\begin{aligned}
& \text { 9- القراءة والتلاوات الدينية. } \\
& \text { • 1 - الرسم والنحت والخط. }
\end{aligned}
$$

11- الغناء والعزف والتلحين والرقص والتمثيل والإخراج والتصوير السينمائي

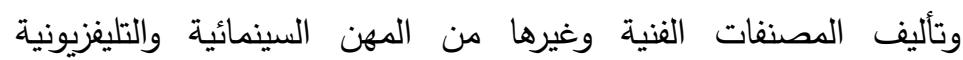

$$
\begin{aligned}
& \text { والإذاعية والمسرحية. } \\
& \text { r } \\
& \text { זן - التخليص الجمركي. }
\end{aligned}
$$

$\varepsilon+1$

المجلة العلمية للاقتصاد والتجارة 


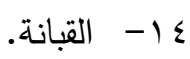

10 - النسخ علي الآلة الكاتبة والكمبيوتر وغيرها بالقطعة لمن يباشر هذا النشاط

$$
\text { بنفسه. }
$$

أما المهن الحرة فقد إختلف الفقهاء في تحديد ماهيتها، وقد وضعت محكمة

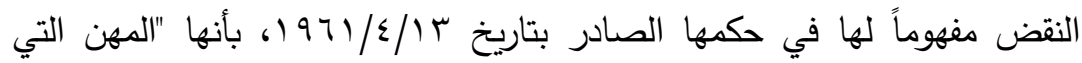
يباشرها الممولين بصفة مستقلة، ويكون العنصر الأساسي فيها العمل، وتقوم علي

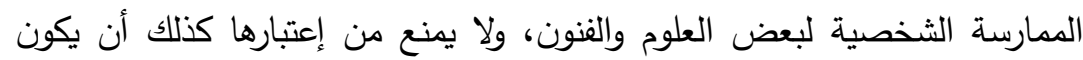

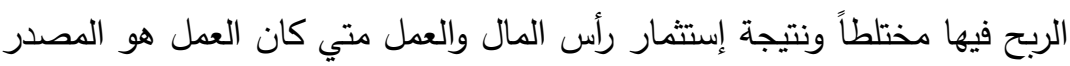

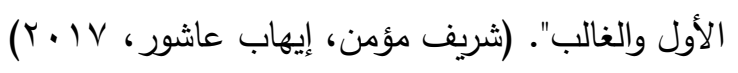

ووفقاً لما ورد بالجدول فإن الخدمات المهنية والإستشارية لا تشمل خدمابك خدمات الحرفيين، ومن ثم فإن ما يتم تأديته من خدمات حرفية يخضع للضريبة بالسعر بران

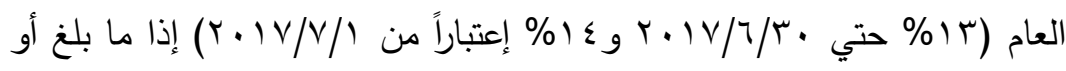

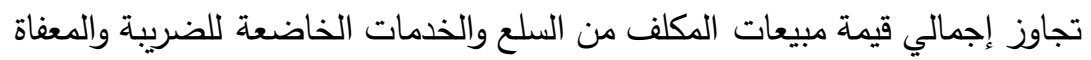
منها حد التسجيل المحدد قانوناً (خمسمائة ألف جنيهاً) مع إعمال قواعد الخصم الضرببي. إلا أنه لم يرد بالقانون أو اللانحة توضيحاً لما هية الخدمات الحرفية.

بناءً علي ما تقدم يري الباحث أن اللأحة لم يرد بها مفهوماً جامعاً مانعاً لما

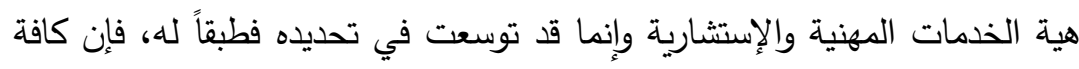

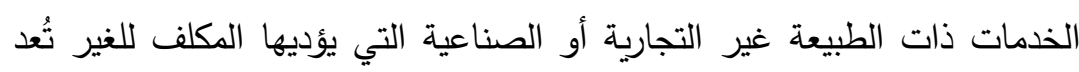

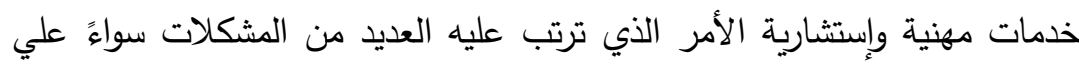

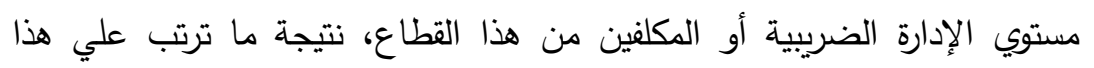

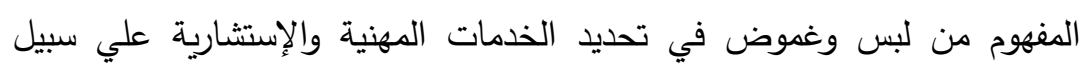


اليقين، فالخدمات التي تقدمها شركات الإدارة لإدارة المنشآت الفندقية أو غيرها من المنشآت هل تعد خدمات مهنية وإستشارية أم من قبيل الخدمات غير الواردة بالجدول، وكذا ما يحصل عليه المرشدين السياحيين عن مزاولتهم مهنة الإرشاد

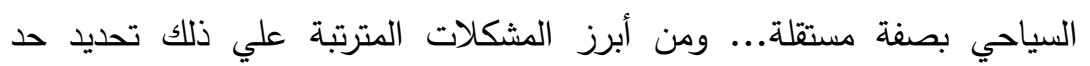

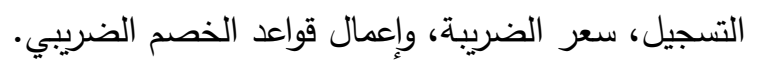

ويقترح الباحث لإزالة أي لبس أو غموض فئل في تحديد الخدمات المهنية

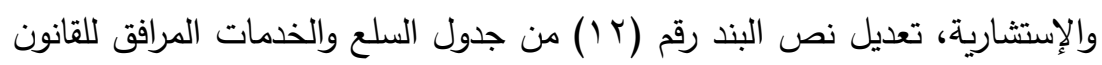
بحث يكون نصه "الخدمات المهنية والإستشارية التي يصدر بتحديدها قرار من

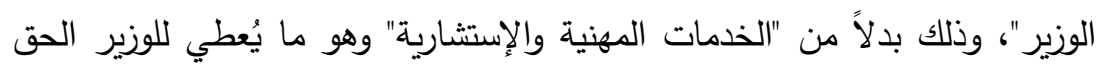

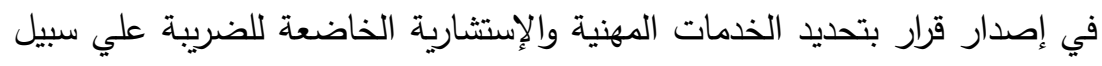
الحصر بما يعمل علي إزالة أي لبس أو غموض في تحديد المكلفين بتحصيل وتوريد الضريبة من هذا القطاع.

\section{ثالثاً: الإطار العام للمحاسبة عن الضريبة علي القيمـة المضـافة في

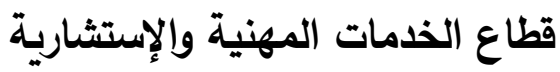

- الأثخاص المكلفون بالضريبة

كل شخص طبيعي أو شخص إعتباري مؤدي لخدمة من الخدمات المهنية

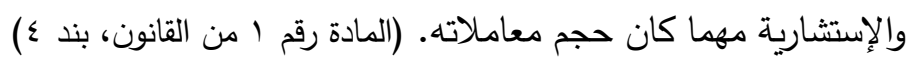

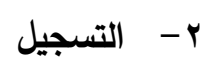

علي كل مؤدي لخدمة من الخدمات المهنية والإستشارية أن يتقدم إلي

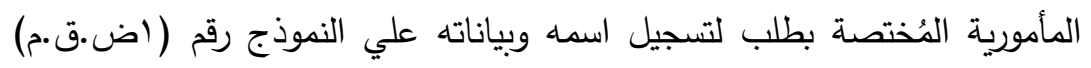

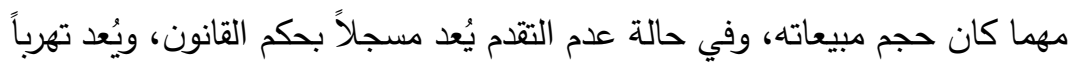

\&.r المجلة العلمية للاقتصاد والتجارة 
من ضريبة الجدول عدم التقدم للمصلحة للتسجيل في المواعيد المحددة. (المواد أرقام

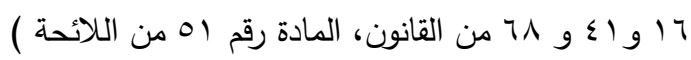

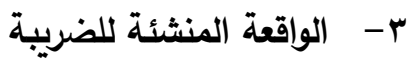

تستحق ضريبة الجدول علي الخدمات المهنية والإستشارية لمرة واحدة عند

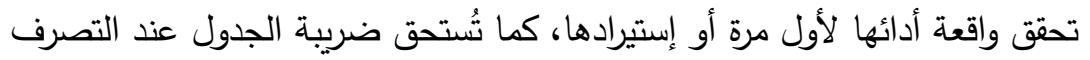

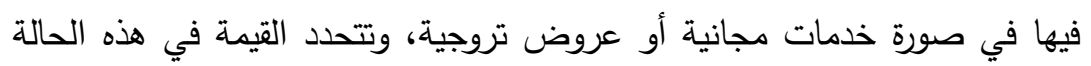

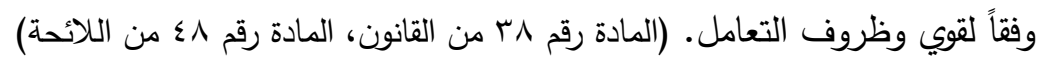
ع - - و وعاء الضريبة تكون القيمة الواجب الإقرار عنها والتي تتخذ أساساً لربط ضريبة الجدول

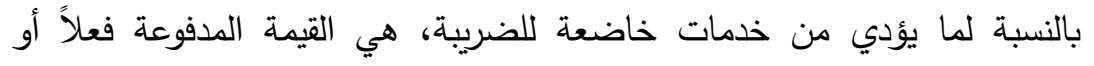

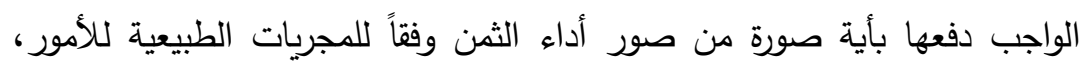
وتتضمن المبالغ التي يتم تحصيلها من متلقي الخدمة تحت أي مسمي طالما كانت بمناسبة أداء الخدمات، وفي حالة أداء خدمة بين أشخاص مرتبطين يجب ألا تقل القيمة عن السعر الذي يتم التعامل به بين شخصين غير مرتبطين وفقاً لقوي السوق ئه

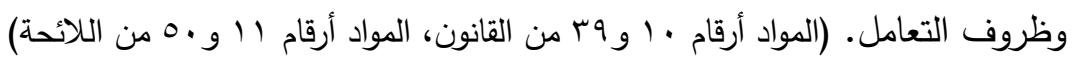
وتضاف قيمة ضريبة الجدول إلى مقابل الخدمات المهنية والإستشارية. (المادة

$$
\text { هـ - مقر لم الضريبة القانون) }
$$

يكون سعر ضريبة الجدول • (\% علي أداء الخدمات المهنية والإستشارية المحلية، ويكون سعر ضريبة الجدول صفر علي الخدمات التي يتم تصديرها، ولا تقرض ضريبة الجدول مرة أخري. (المادة رقم ؟ب من القانون، المادة رقم ه؛ من اللائحة) 


$$
\text { צ- خصم الضريبة }
$$

لا تسري أحكام خصم الضريبة (المردودات، المدخلات) علي ضريبة الجدول،

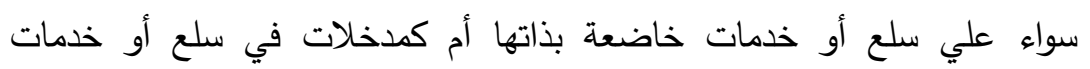

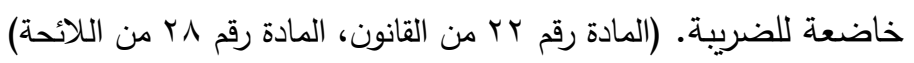

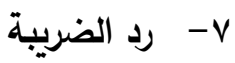

للمسجل الحق في رد الضريبة السابق سدادها على الآلات والمعدات التي

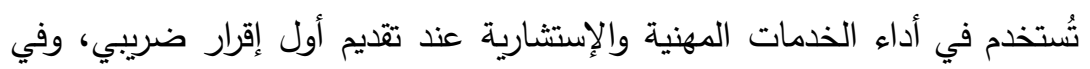
حالة التصرف في الآلات أو المعدات السابق رد الضريبة عليها أو إستخدامها في

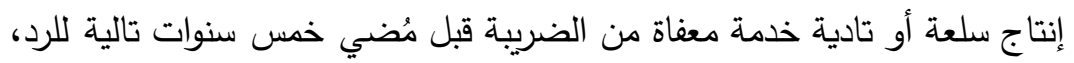

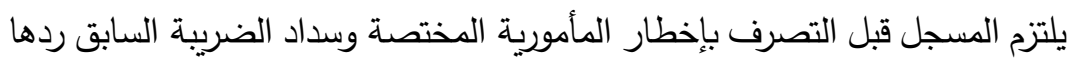

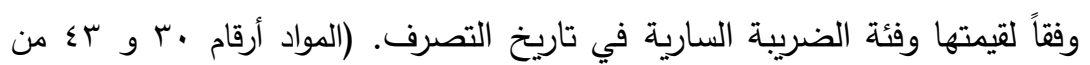

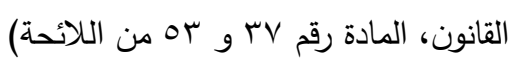
للمسجل الحق في تسوية الضريبة السابق سدادها علي أجزاء الآلات

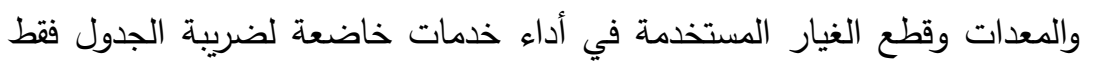
من قيمة ضريبة الجدول في حدود المستحق منها حتي يتم إستنفاذها. (المادة رقم

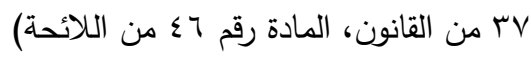

$$
\text { 9- - الإقرار الضريبي الثهري }
$$

علي كل مسجل أن يُقدم للمأمورية المختصة إقراراً شهرياً عن ضريبة الجدول المستحقة وذلك علي النموذج رقم ـاض.ق.م خلال الشهرين التاليين لإنتهاء الفترة

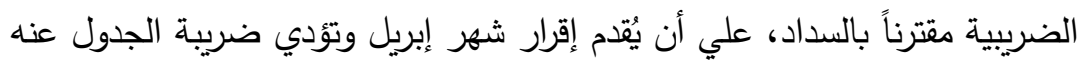
في موعد غايته اليوم الخامس عشر من شهر يونيو. كما يلتزم المسجل بتقديم هذا فئرئ

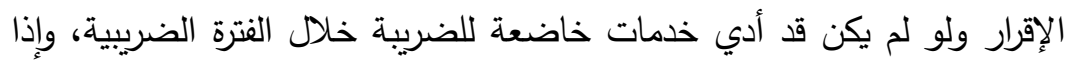


وافق انتهاء المدة المقررة لتقديم الإقرار عطله رسمية فيعتبر أول يوم عمل تال للعطلة متمما لهذه المدة. وإذا لم يُقدم المسجل الإقرار في الميعاد المحدد قانوناً يكون للمصلحة الحق في تقدير الضريبة عن الفترة الضريبية مع بيان الأسس التي إستتدت إليها في التقدير ، وذلك كله دون الإخلال بالمساءلة الجنائية. (المادة رقم

$$
\begin{aligned}
& \text { ـ ا من القانون، المادة رقم } 17 \text { من اللأئحة) } \\
& \text { • } 1 \text { - تعديل الإقرار الضربيجي }
\end{aligned}
$$

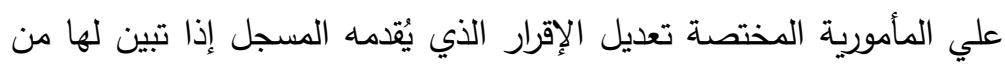

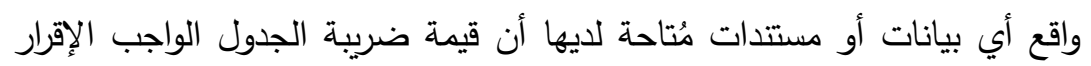
عنها تختلف عما ورد بالإقرار عن أية فترة ضريبية وإتخاذ الإجراءات القانونية لتحصيل ما يستحق، وذلك خلال خمس سنوات تبدأ من تاريخ إنتهاء المدة المحددة

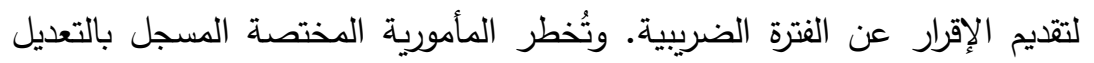
والأسس التي استتد عليها علي النموذج هاض.ق.م بخطاب موصي عليه مصحوباً بعلم الوصول أو بأية وسيلة إلكترونية لها حجية في الإثبات وفقاً لقانون التوقيع الإلكتروني أو بأية وسيلة كتابية يتحقق بها العلم اليقيني. ولصاحب الثأن، الطعن في تقدير المصلحة وفقاً للإجراءات المنصوص وسئه

عليها في القانون. (المادة رقم 10 من القانون، المادة رقم لإن من اللائحة التنفيذية) ولا يجوز للمصلحة إجراء تقدير الضريبة أو ضريبة الجدول أو تعديل الإقرار

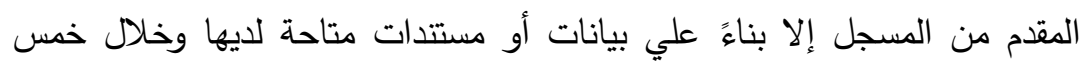

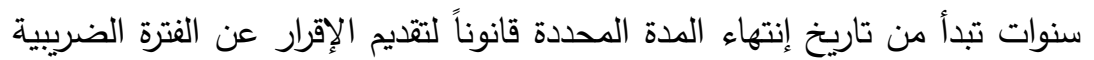

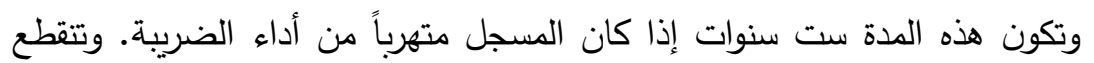

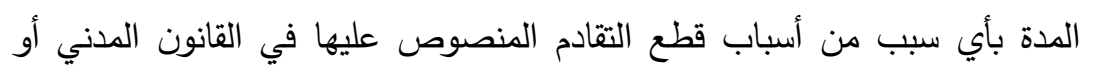

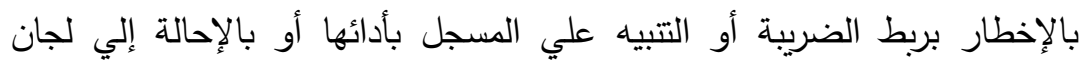

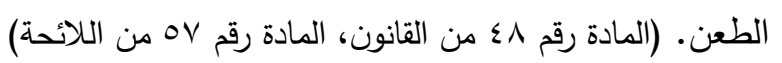


1 - الضريبة الإضافية (المواد أرقام 1 و 10 من القانون، المادة رقم VI من اللائحة)

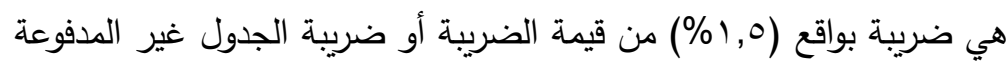
بما فيها الضرببة الناتجة عن تعديل الإقرار ، وذلك عن كل شهر أو جزء منه إعتباراً

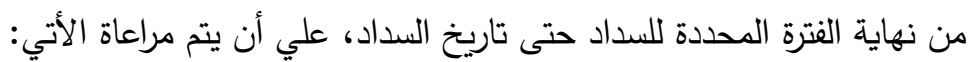

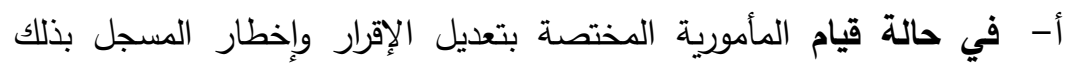
خلال الثلاث سنوات الأولي التي تبدأ من تاريخ إنتهاء المدة الدحددة قانوناً

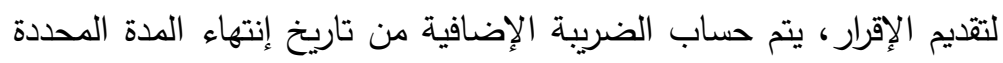

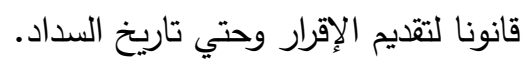
ب- في حالة قيام المأمورية المختصة بتعديل الإقرار بعد مضي الثباري الثلاث سنوات

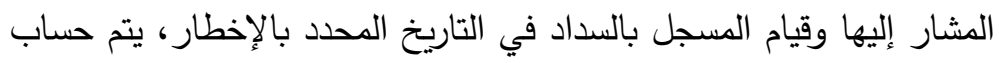
الضريبة الإضافية عن مدة الثلاث سنوات المذكورة فقط، وفي حالة عدم قيام

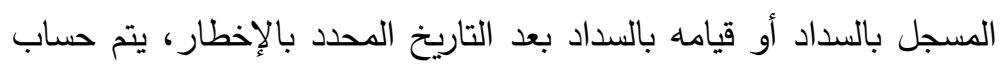

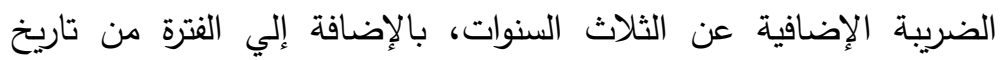
الإخطار وحتي تاريخ السداد. r ا ا - تحصيل الضريبة علي المسجل أداء حصيلة ضريبة الجدول دورياً للمصلحة رفق إقراره الثهري

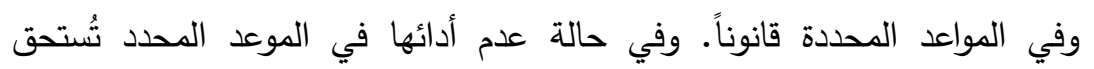
الضريبة الإضافية ويتم تحصيلها مع ضرببة الجدول وبذات إجراءاتها. (المواد أرقام ع و اب من القانون، المادة رقم وب من اللائحة) rا - الطعن علي تعديل أو تقدير الضربية

(المادة رقم 7 من القانون، المادة رقم ال؟ من اللائحة)

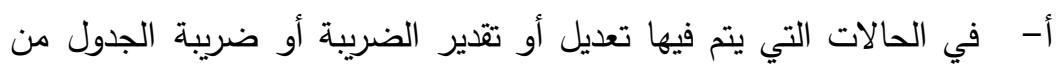
المصلحة يتم إخطار المسجل بذلك بخطاب موصي عليه مصحوباً بعلم 
الوصول أو بأية وسيلة إلكترونية لها حجية في الإثبات وفقاً لقانون التوقيع الاكتروني أو بأية وسيلة كتابية يتحقق بها العلم اليقيني بذلك التعديل أو التقدير.

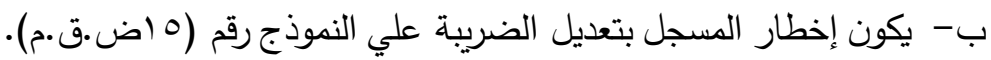
ج- في حالة تقدير الضريبة لعدم تقديم المسجل للإقرار الضريبي يكون الإخطار

$$
\text { على النموذج رقم (ء ا ض. ض.ق.م). }
$$

دـ - يكون للمسجل الطعن على ذلك التعديل أو التقدير خلال ثلاثين يوماً من تاريخ علمه بهذا التعديل أو التقدير. هـ - في حالة ورود علم الوصول بما يفيد الإستلام دون أن يتم الطعن خلال المدة المشار إليها، يُعتبر تعديل أو تقدير الضريبة من قبل المصلحة المهائل فئياً.

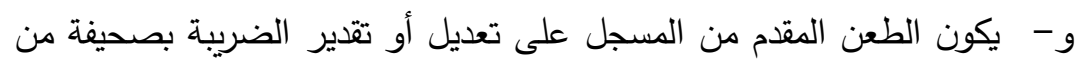
ثلاث صور يودعها المأمورية المختصة وتُّلم إحداها للمسجل مؤشراً عليها

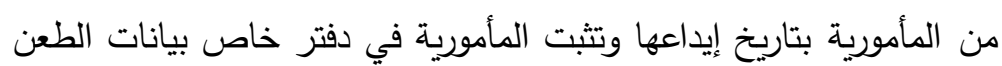
وملخصاً بأوجه الخلاف التي تتضمنها، علي أن تقوم بإحالته للجنة الداخلية أ- تقوم اللجنة الداخلية بالبت في ذلك الطعن خلال ستين يوما من تاريخ تقديم الطعن، فإذا تم التوصل الى تسوية أوجه الخلاف تُصبح الضريبة نهائية، وإذا لم

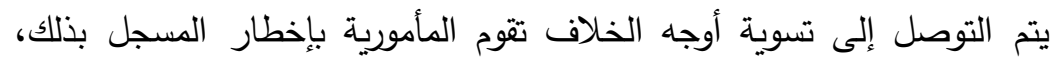

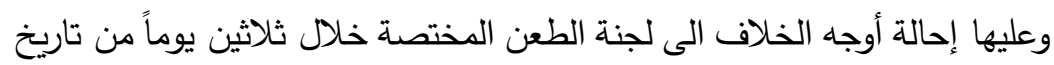

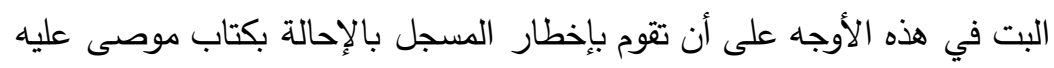

$$
\text { مصحوباً بعلم الوصول. مده الاوجه }
$$
ب- - وإذا انقضت مدة الثلاثين يوماً دون قيام المأمورية بإحالة الخلاف إلى لجنة المدان الطعن المختصة، كان للمسجل أن يعرض الأمر كتابة على رئيس هذه اللجنة 
مباشرة أو بكتاب موصى عليه مصحوباً بعلم الوصول خلال خمسة عشر يوماً من

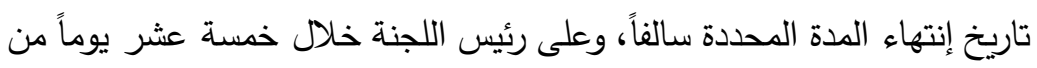
تاريخ عرض الأمر عليه أو وصول كتاب المسجل إليه أن يحدد جلسة لنظر النزاع

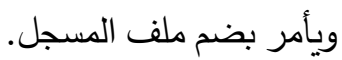

ج-ويجوز إتخاذ أي من الإجراءات المنصوص عليها سالفاً بأية وسيلة الكترونية يحددها الوزير.

د - ويُعتبر تعديل أو تقدير الضرببة من قبل المصلحة نهائياً إذا لم يُقدم الطعن خلال المواعيد المشار إليها. لجنة الطعن (المواد أرقام ^ه و وه هو ـ ـ الج من القانون)

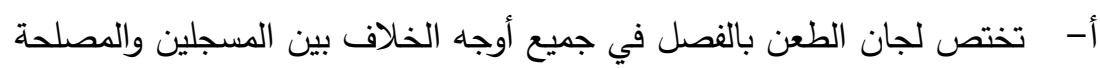
في المنازعات المتعلقة بالضرائب المنصوص عليها في القانون.

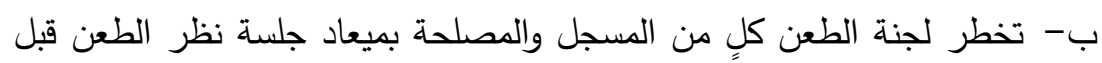

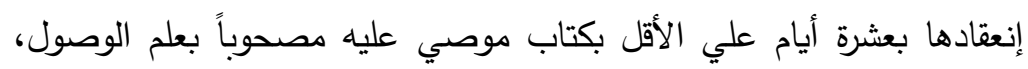

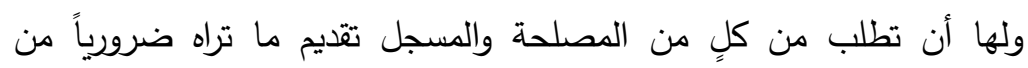

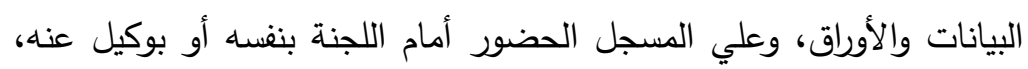
وإلا فصلت اللجنة في الطعن في ضوء المستتدات المقدمة.

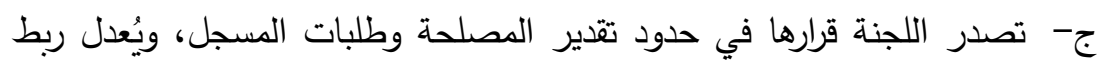
الضريبة وفقاً لقرار اللجنة، فإذا لم تكن الضريبة قد حُصلت فيكون تحصيلها بموجب هذا القرار. د- - يُعلن كلٍ من المسجل والمصلحة بالقرار الذي تصدره اللجنة بكتاب موصي عليه

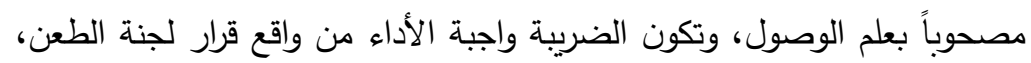
ولا يمنع الطعن في قرار اللجنة أمام المحكمة المختصة من تحصيل الضريبة. 
هـ - لكلٍ من المصلحة والمسجل الطعن في قرار اللجنة أمام المحكمة المختصة خلال ستين يوماً من تاريخ الإعلان بالقرار .

؛ 1 - المخالفات والتهرب من الضريبة

\begin{tabular}{|c|c|}
\hline 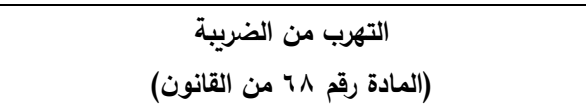 & 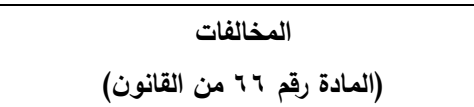 \\
\hline يعد تهرباً من الضريبة وضريبة الجدول ما يلي: & \\
\hline 1- عدم التقدم للمصلحة للتسجيل في المواعيد المحددة. & مخالفة الأحكام والإجراءات أو النظم المنصوص \\
\hline r- بيع السلعة أو أداء الخدمة أو إستيراد أي منهما & عليها في هذا القانون ولائحته التنفيذية دون \\
\hline دون الإقرار عنها، وسداد الضريبة وضريبة الجدول & أن تكون عملاً من أعمال التهرب المنصوص \\
\hline 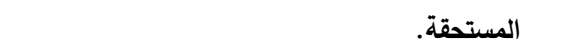 & عليها فيه، وتُعد مخالفة لأحكام هذا القانون \\
\hline r- خصم الضريبة أو ضريبة الجدول كلياً أو جزئياً دون & الحالات الآتية: \\
\hline وجه حق بالمخالفة لأحكام وحدود الخصم. & التأخير في تقديم الإقرار وأداء الضريبة \\
\hline ؛ - إسترداد الضريبة أو ضريبة الجدول كلها أو بعضها & وضريبة الجدول عن المدة المحدة في \\
\hline دون وجه حق مع العلم بذلك. & المادة (؛ 1) من القانون بما لا يجاوز \\
\hline ه- تقديم مستندات أو سجلات مزوة أو مصطنعة & ستين يوماً. \\
\hline للتخلص من سداد الضريبة وضريبة الجدول كلها أو & تقديم بيانات خاطئة عن المبيعات من \\
\hline بوضها. & السلع أوالخدمات الخاضعة للضريبة \\
\hline צ-عدم إصدار المسجل فواتير عن مبيعاته من السلع & إذا ظهرت فيها زيادة عما ورد بالإقرار. \\
\hline أو الخدمات الخاضعة للضريبة وضريبة الجدول. & r- ظهور عجز أو زيادة في السلع \\
\hline v- إنقضاء ستين يوماً علي إنتهاء المواعيد المحددة & المودعة في المناطق والأسواق الحرة \\
\hline لسداد الضريبة وضريبة الجدول دون الإقرار عنها & بالمخالفة لأحكام قانون الجمارك. \\
\hline 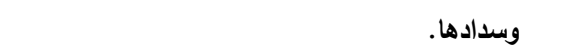 & عدم إخطار المصلحة بالتغييرات التي \\
\hline ^- - إصدار غير المسجل لفواتير محملة بالضريبة & حدثت علي البيانات الواردة بطلب \\
\hline وضريبة الجدول. & التسجيل خلال الموعد المحدد. \\
\hline 9 - عدم الإلتزام بالقواعد والإجراءات والضوابط التي & هـ - عدم تمكين موظفي المصلحة من \\
\hline تكفل إنتظام إصدار الفواتير وفقاً لأحكام المادة & القيام بواجباتهم أو ممارسة \\
\hline (r ا ) من هذا القانون. & إختصاصهم في الرقابة والتفتيش \\
\hline • 1- إصطناع فواتير للغير دون أن تكون صادرة عن & والمعاينة والمراجعة وطلب المستندات \\
\hline عمليات بيع حقيقية، وتقع المسئولية بالتضامن بين & أو الإطلاع عليها. \\
\hline مصدر الفاتورة المصطنعة والمستفيد منها. & \\
\hline
\end{tabular}

§.

المجلة العلمية للاقتصاد والتجارة 


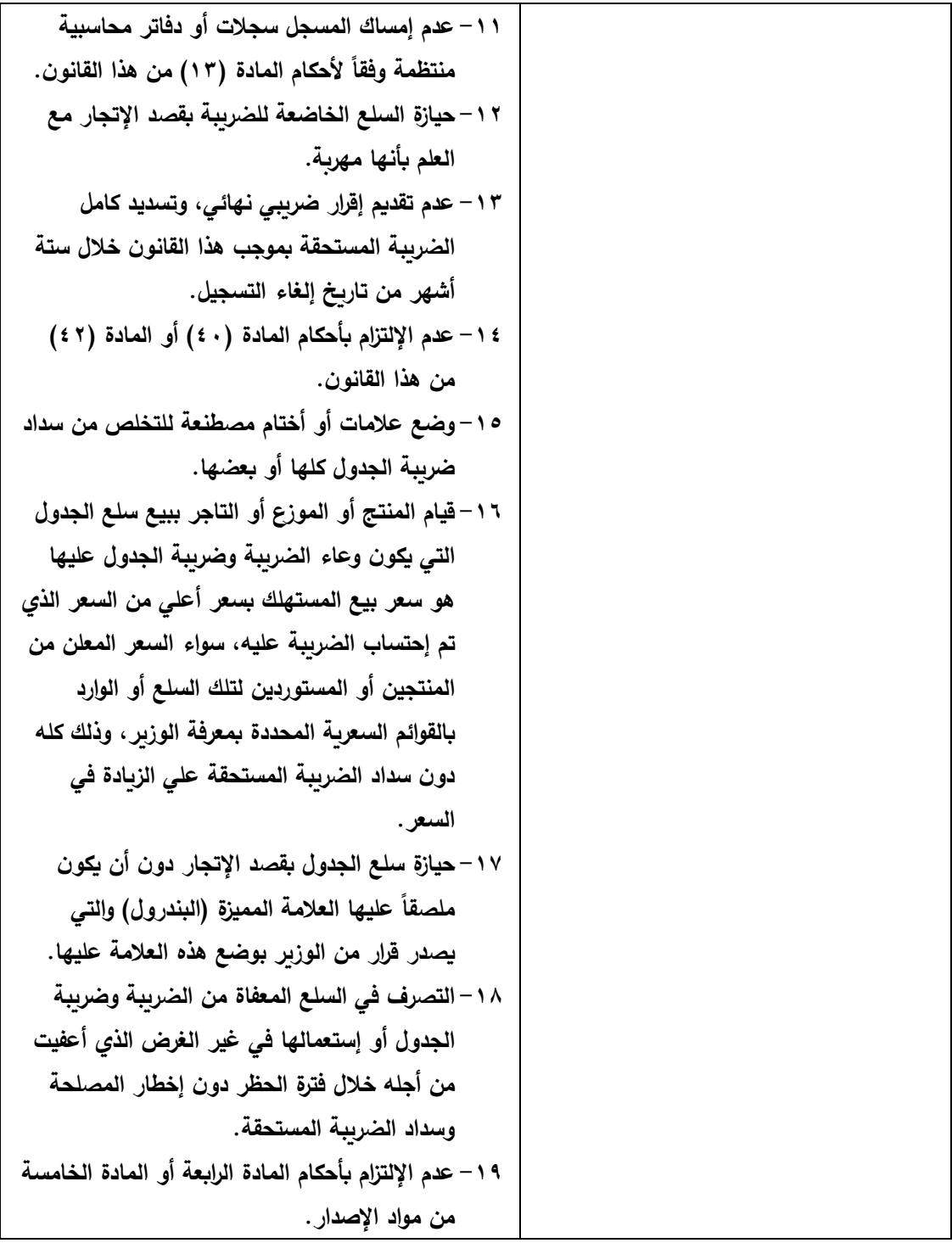

$\{11$

المجلة العلمية للاقتصاد والتجارة 


\begin{tabular}{|c|c|}
\hline عقوبة التهرب & عقوبة المخالفات (مادة ז 7) \\
\hline 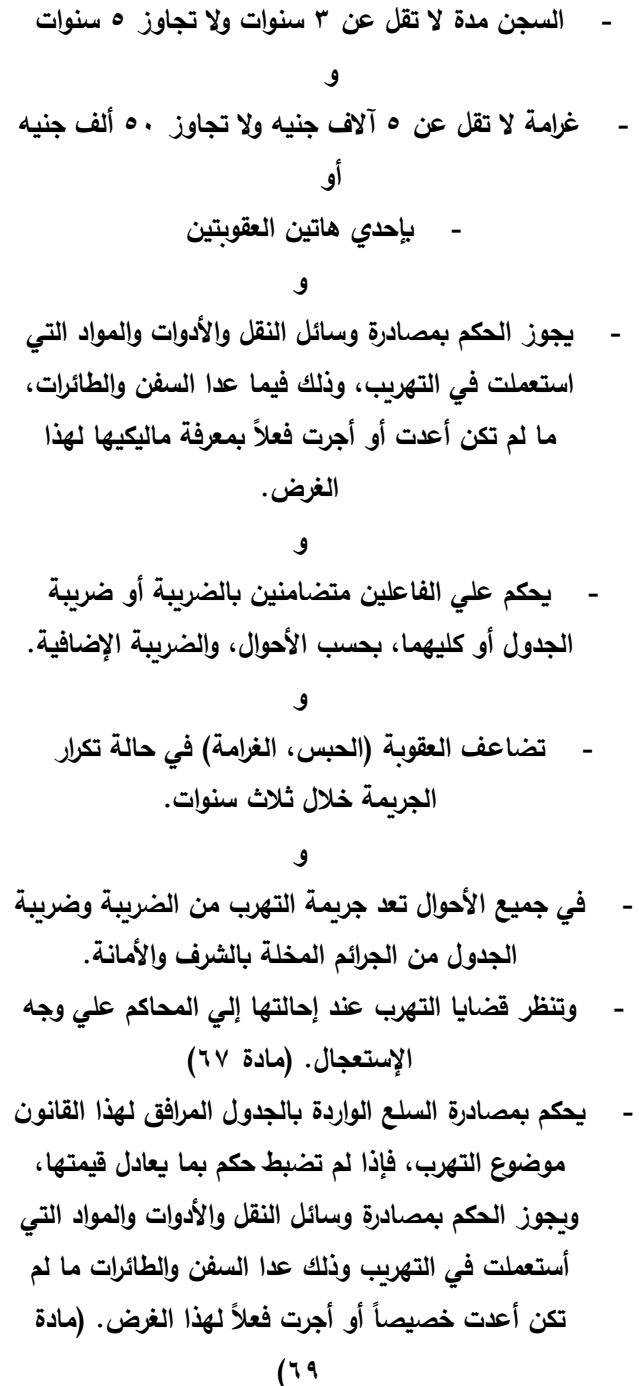 & 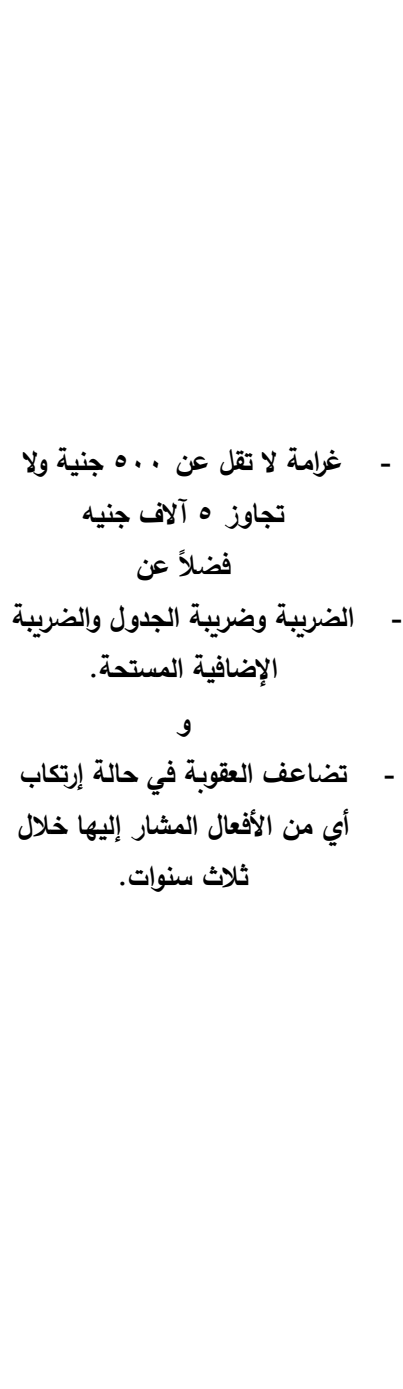 \\
\hline
\end{tabular}


رابعاً: مُشكلات المحاسبة عن الضريبة علي القيمة المضافة في قطاع

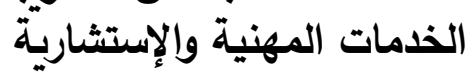

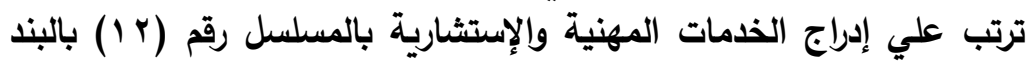

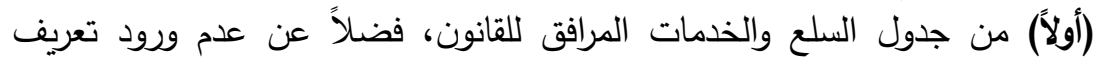

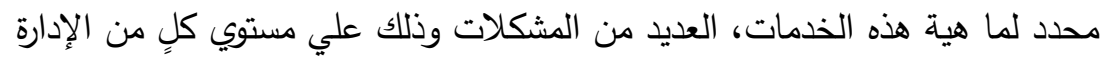

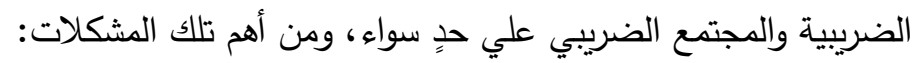

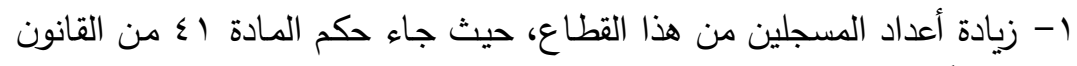

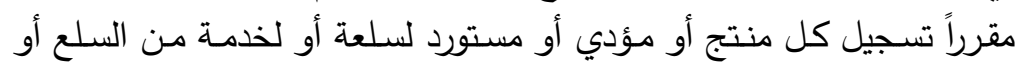

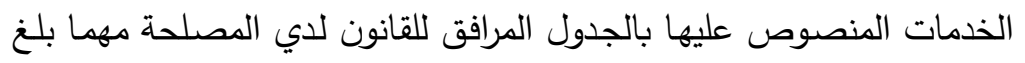

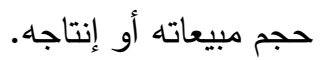
r- إرتقاع تكلفة تحصيل الضريبة من هذا القطاع، نتيجة لتسجيل مؤدي الخذمات

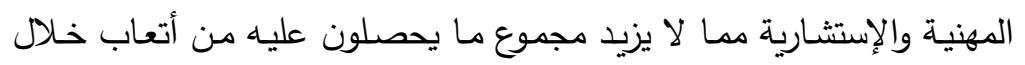

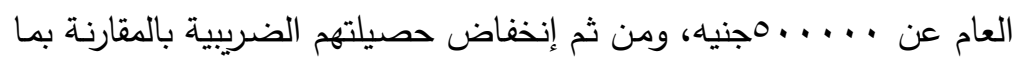

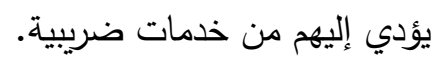

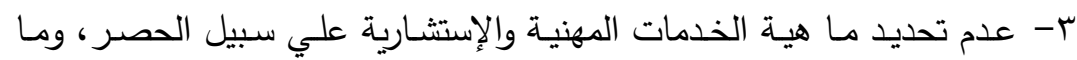

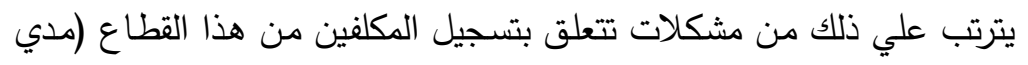

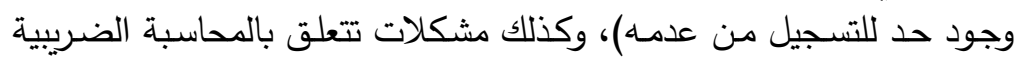

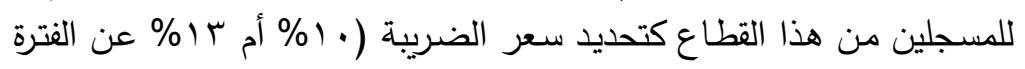

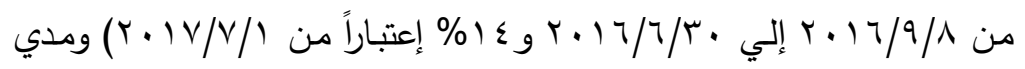
تطبيق قواعد خصم الضريبة.

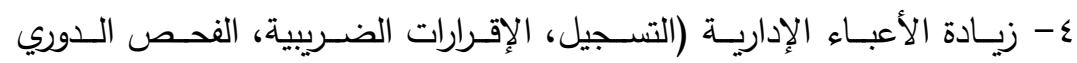

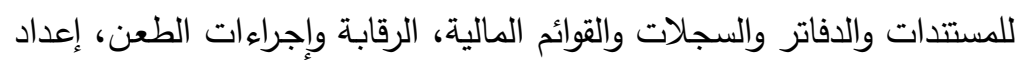

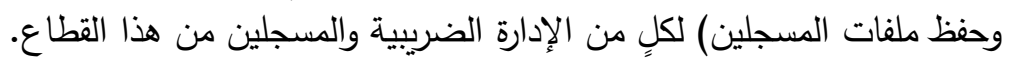

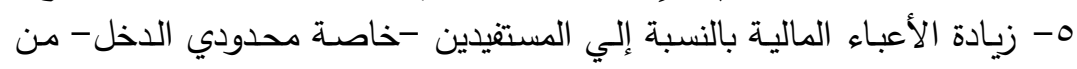

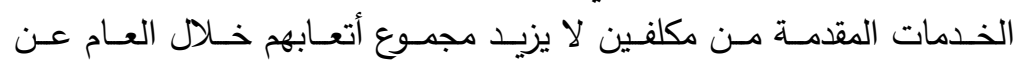

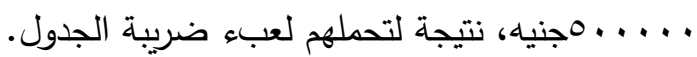


צ- عدم خصم الضـريبة السـابق سدادها علي المدخلات، المستخدمة في تأديـة الخدمات المهنية والإستشارية.

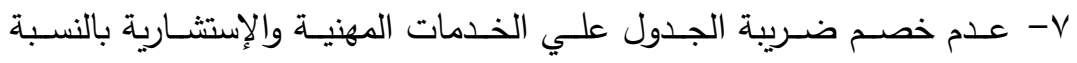
للمسجلين المستثيدين من هذه الخدمات.

خامساً: الأسلوب المُقترح للمحاسبة عن الضريبة علي القيمة المضافة في

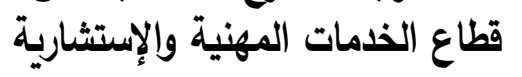

يري الباحث أن تتم المحاسبة عن الضريبة علي القيمة المضافة والإستهاته في قطاع

الخدمات المهنية والإستشارية بتطبيق ذات القواعد التي يتم تطبيقها علي الخدمات

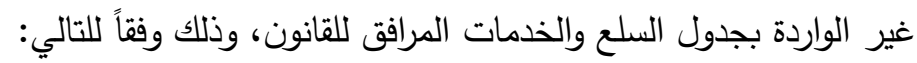

1- الأشخاص المكلفون بالضريبية

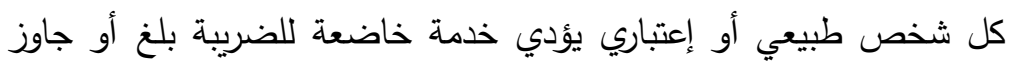

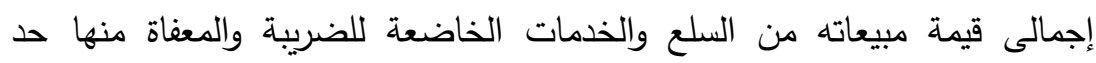

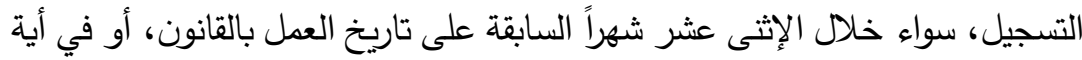
سنة مالية أو جزء منها بعد العمل بالقانون.

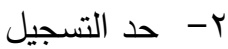
حدده القانون بمبلغ خمسمائة ألف جنيه، ويجوز بقرار من الوزير تعديله.

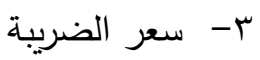

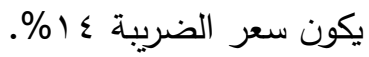

$$
\text { ع - - خصم الضربية }
$$

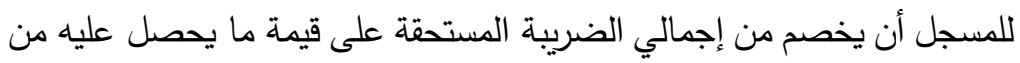

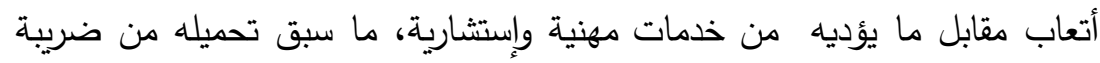

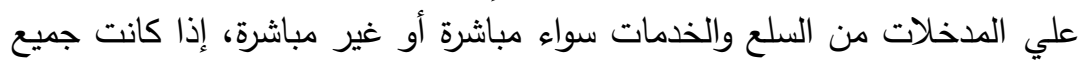
مبيعاته خلال الفترة الضريبية خاضعة للضريبة الضية. 


\section{ساداً: الخلاصة والنتائج وإلتوصيات}

الخلاصة

تتاول الباحث أهم مُشكلات المحاسبة عن الضريبة علي القيمة المضافة التى تواجه كلٍ من الإدارة الضريبية والمسجلين من قطاع الخدمات المهنية والإستشارية

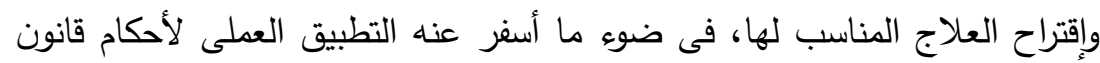

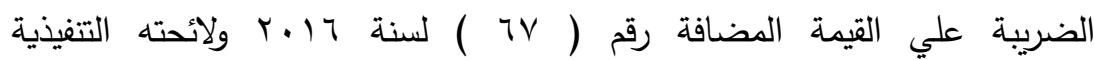

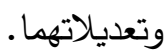

(النتائج

- تعاني الإدارة الضريبية والمسجلين من قطاع الخدمات المهنية والإستشارية العديد

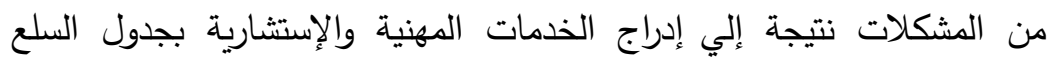

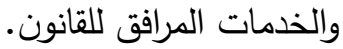

- - من أهم المُشكلات المُترتبة علي إدراج الخدمات المهنية والإستشارية بجدول

السلع والخدمات المرافق للقانون:

ل عدم تحديد ما هية الخدمات المهنية والإستشارية علي سبيل الحصر .

ل زيادة أعداد المسجلين من هذا القطاع.

、 $\quad$ إرتفاع تكلفة تحصيل الضريبة.

ل ح زيادة الأعباء الإدارية لكلٍ من الإدارة الضريبية والمسجلين من هذا القطاع.

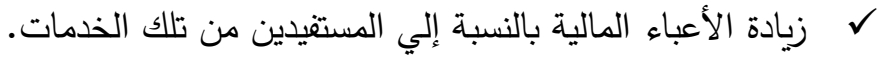

、 ع عدم خصم الضريبة علي المدخلات.

ل عدم خصم الضريبة علي الخدمات المهنية والإستشارية.

- - هناك حاجة إلي تطوير أسلوب المحاسبة عن الضريبة علي القيمة المضافة في

قطاع الخدمات المهنية والإستشارية.

$\varepsilon 10$

المجلة العلمية للاقتصاد والتجارة 


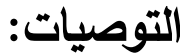

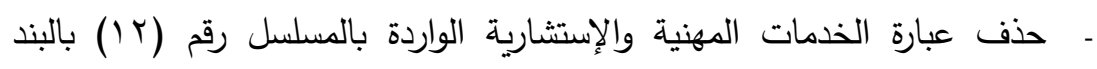

$$
\text { (أولاً) من جدول السلع والخدمات المرافق للقانون. }
$$

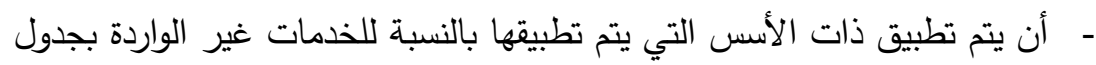

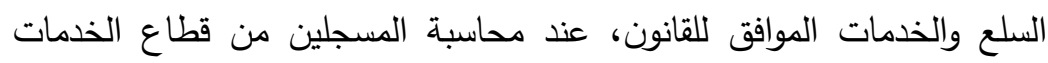

$$
\text { المهنية والإستشارية. }
$$

أو أول

- تعديل نص البند رقم (r) من جدول السلع والذدمات المرافق للقانون بحيث

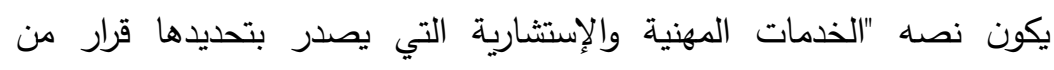

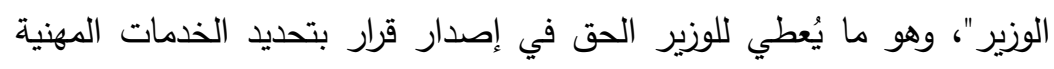

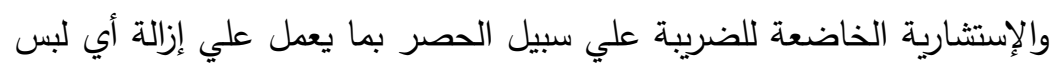

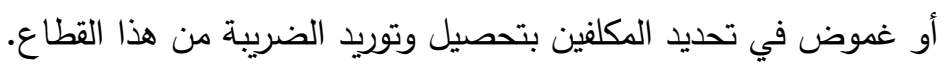

\section{الاراسات المستقبلية}

- مُشكلات رد الضريبة علي القيمة المضافة وإقتراح العلاج المناسب وفقاً لأحكام

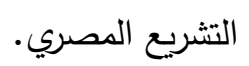




\section{المراجع}

1- شريف محمد مؤمن، إيهاب محمد كامل عاشور، المحاسبة الضربيية علي

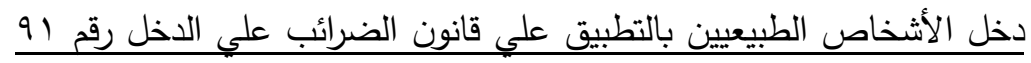

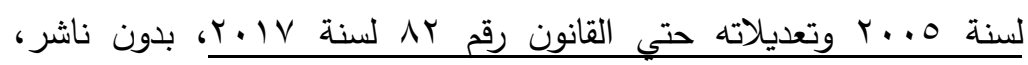

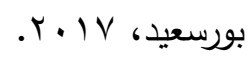

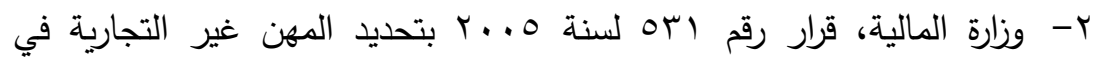
تطبيق حكم المادة (••) من قانون الضريبة علي الدخل الصادر بالقانون رقم

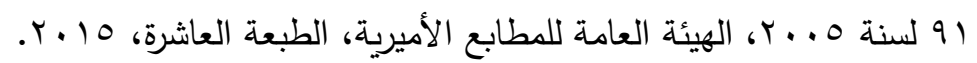

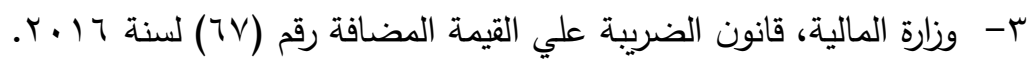

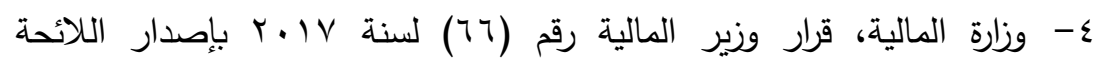
التتفيذية لقانون الضريبة علي القيمة المضافة، المادة رقم (YT). 
